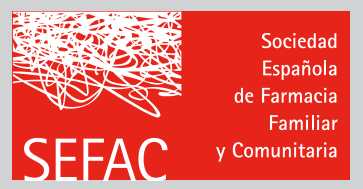

\title{
Test COVID-19 en farmacias: ¿por qué no?
}

\author{
Navidad Sánchez Marcos
}

Vicepresidenta de SEFAC Madrid.

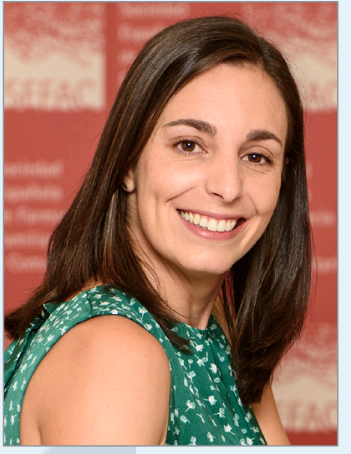

Navidad Sánchez Marcos

\section{PALABRAS CLAVE}

COVID-19, farmacias, test

\section{KEYWORDS}

COVID-19, pharmacies, test
Nuestro país tiene una incidencia de COVID-19 cada vez más alta. El número de contagios no deja de crecer, el sistema sanitario está de nuevo a punto del colapso, la atención primaria está saturada, las consultas externas de muchos hospitales se han suspendido, se realizan solo procedimientos urgentes... La situación actual requiere del aprovechamiento de todos los recursos disponibles. ¿Dónde estamos los farmacéuticos comunitarios? Trabajando.

Seguimos siendo los profesionales sanitarios más accesibles, los únicos cuyas puertas no han cerrado. Cualquier persona en España puede acceder libremente a cualquiera de las 22.102 farmacias comunitarias que cubren el territorio nacional, y encontrará un profesional sanitario que no solo desarrolla servicios profesionales farmacéuticos asistenciales (SPFA) orientados al proceso de uso de los medicamentos, sino también los servicios relacionados con la salud comunitaria.

Dentro de los SPFA definidos por Foro AF-FC relacionados con la salud comunitaria (1), no solo se encuentra la promoción de la salud y la educación sanitaria, también se desarrolla la prevención de la enfermedad mediante cribados, detección de enfermedades ocultas/ riesgo de enfermedad, participación en programas de inmunización y el apoyo colaborativo al diagnóstico por el médico.

En consecuencia, ante la evolución actual de la pandemia, es necesario que los farmacéuticos comunitarios podamos sumar en la estrategia de control de la COVID-19. No hacerlo sería despreciar un gran recurso.

Ante la propuesta de incorporación del farmacéutico en el abordaje y detección de pacientes con SARS-CoV-2, los farmacéuticos comunitarios nos hemos encontrado obstáculos que, como buenos corredores de fondo, hemos sabido superar:
1. ¿Están realmente los

farmacéuticos dispuestos a colaborar?

En una encuesta realizada por SEFAC a sus socios en relación con las pruebas rápidas de COVID-19, el 90,2 \% de los socios participantes reflejó que estaría dispuesto a hacer estas pruebas si se dieran las condiciones necesarias. Y no solo eso, tanto SEFAC como otros organismos farmacéuticos han manifestado en reiteradas ocasiones la voluntad del colectivo de ponerse a disposición de las autoridades para ayudar en el abordaje de la pandemia.

\section{2. ¿Es necesaria la prestación del servicio?}

Sí. Estamos ante un momento crítico. Continúa el crecimiento del número de casos, el número de ingresos hospitalarios, ocupación de las camas UCI, la situación es apremiante y es necesario aprovechar todos los recursos disponibles y los farmacéuticos somos un recurso infrautilizado para atender a la población y descongestionar los centros de salud.

\section{3. ¿Existe una demanda por parte} de los usuarios?

A pesar de no ser un servicio aún implantado en las farmacias, es una realidad que muchos de nosotros recibimos la petición por parte de nuestros pacientes: personas que tienen sintomas menores compatibles, contactos estrechos de casos confirmados, visitas a familiares, incorporaciones al trabajo, entre otros.

\section{4. ¿Disponemos de un espacio adecuado?}

La gran mayoría de las farmacias ya disponen de una zona de atención personalizada (ZAP), espacio que permite la realización de la prueba con garantías de seguridad, tanto para el paciente como para el profesional que la realiza, permitiendo además la necesaria confidencialidad de 
los resultados. En la encuesta realizada por SEFAC el $77 \%$ de los farmacéuticos participantes manifestó que la farmacia en la que trabaja cuenta con las instalaciones adecuadas para realizar los test rápidos de detección de anticuerpos frente al coronavirus SARS-CoV-2.

\section{5. ¿Qué tipo de test se puede realizar?}

Desde farmacia comunitaria se pueden realizar test de anticuerpos y/o test de antígenos.

Los test de anticuerpos permiten conocer el estado de inmunidad o seroprevalencia del paciente. En este tipo de prueba se determina la presencia de anticuerpos IgM e IgG generados como respuesta al virus y puede realizarse con una muestra de sangre obtenida por punción digital. Mientras que los test de antígenos tienen como finalidad determinar la presencia del virus en el paciente y requieren una muestra nasofaríngea o de saliva.

En ambos casos el tiempo de obtención del resultado no supera los 15 minutos, permitiendo acortar plazos con respecto a las muestras analizadas mediante PCR que en la Comunidad de Madrid han alcanzado una demora de hasta 7 días.

Acortar plazos en la detección de pacientes positivos es clave para frenar la trasmisión comunitaria, permitiendo el aislamiento domiciliario precoz de los pacientes que experimentan los primeros síntomas, así como la identificación de los pacientes asintomáticos.

\section{6. ¿Existen test de suficiente calidad? ¿Son fiables?}

La calidad y la fiabilidad ha sido uno de los motivos de duda con respecto a la posible utilidad real de los test rápidos en el inicio de la pandemia. Actualmente están disponibles en el mercado test de anticuerpos con una fiabilidad superior al $98 \%$ y test de antígenos en eficacia equiparable a los resultados obtenidos mediante PCR.

\section{7. ¿Tenemos los farmacéuticos formación}

y capacidad técnica para su realización?

Los farmacéuticos comunitarios ya realizamos medidas de parámetros clínicos mediante química seca (perfil lipídico, glucemia, hemoglobina glicosilada...), para lo que nuestro título universitario nos habilita. Pero además de nuestra formación básica SEFAC ha desarrollado un curso específico de pruebas rápidas de Covid-19. Del mismo modo, desde hace años las farmacias vienen colaborando en distintas comunidades autónomas en la realización de pruebas similares, como pueden ser las del VIH.

\section{8. ¿Y la gestión de los residuos generados?}

No debe ser un problema, el 47,2 \% de los farmacéuticos dispone ya de un contenedor de residuos biosanitarios y servicio de recogida y gestión de los residuos adecuado.
9. ¿Y la interpretación de los resultados?

A pesar de lo expresado por algunas instituciones, la interpretación de los resultados es sencilla. En el caso de los test de anticuerpos podemos enfrentarnos a cuatro posibles resultados y en cuanto a los test de antígenos a dos. El Ministerio de Sanidad ha establecido el protocolo que se debe seguir en cada uno de ellos.

10. ¿Cómo comunico el resultado al paciente? ¿y al Sistema Nacional de Salud? ¿Es de declaración obligatoria?

El resultado de la prueba debe ser comunicado al paciente y en el caso de que confirme que el paciente tiene infección activa se deriva a su médico de atención primaria para que se ponga en marcha el protocolo de aislamiento y rastreo de contactos estrechos. Se acompañará del ofrecimiento de la atención farmacéutica domiciliaria y del seguimiento del paciente, así como la indicación farmacéutica para la resolución de síntomas menores.

Toda comunicación del resultado obtenido debe acompañarse de la educación sanitaria correspondiente, información sobre medidas de protección y/o aislamiento domiciliario.

\section{1. ¿Es necesario un registro?}

Sí, en una plataforma on line que permita la comunicación inmediata con la autoridad sanitaria correspondiente, así como el registro interno de la farmacia en la plataforma SEFAC e_XPERT.

\section{2. ¿Hay respaldo legal?}

Actualmente no. Este es el único punto que falta para que la farmacia comunitaria pueda sumar esfuerzos para el control de la pandemia, pero lamentablemente es el único que no depende del farmacéutico comunitario.

Por lo tanto, ¿es posible realizar las pruebas rápidas de COVID-19 en las farmacias comunitarias españolas? Técnicamente sí, el único impedimento es la legislación, pero confío en que haya voluntad política para que la normativa se adapte a las necesidades actuales y nos permita sumar esfuerzos y ayudar en la detección de los casos de COVID-19, porque el único objetivo del farmacéutico comunitario es mejorar la calidad de vida de las pacientes.

\section{Referencias bibliográficas}

1. Foro de Atención Farmacéutica-Farmacia Comunitaria (Foro AF-FC). Guía práctica para los Servicios Profesionales Farmacéuticos Asistenciales en la Farmacia Comunitaria. Madrid. Consejo General de Colegios Oficiales de Farmacéuticos; 2019. Disponible en: https://www.portalfarma.com/ inicio/serviciosprofesionales/forofarmaciacomunitaria/Documents/2019-guia-practica-spfa.pdf 